\title{
Environmental Pollution to Blame for Depressive Disorder?
}

\author{
Mariana Segovia-Mendoza ${ }^{a}$, Margarita Isabel Palacios-Arreolab ${ }^{b}$, Lenin Pavónc, Enrique Becerrilc, Karen Elizabeth \\ Nava-Castro ${ }^{\mathrm{b}}$, Omar Amador ${ }^{\mathrm{b}}$, Jorge Morales-Montor ${ }^{\mathrm{d} *}$.
}

1 Departamento de Farmacología, Facultad de Medicina, Universidad Nacional Autónoma de México, Ciudad de México, México; mariana.segovia@facmed.unam.mx

2 Departamento de Mutagénesis y Genotoxicidad Ambientales, Centro de Ciencias de la Atmósfera, Universidad Nacional Autónoma de México, Ciudad de México, México.; mi.palacios.arreola@gmail.com, karlenc@atmosfera.unam.mx, oam@atmosfera.unam.mx

3 Laboratory of Psychoimmunology, National Institute of Psychiatry "Ramón de la Fuente", Calzada MéxicoXo-chimilco 101, Colonia San Lorenzo Huipulco, Tlalpan, 14370 Mexico City, Mexico. lenin.pavon@inp.gov.mx; lusenbeve@insp.gov.mx

4 Departamento de Inmunología, Instituto de Investigaciones Biomédicas, Universidad Nacional Autónoma de México, Ciudad de México, México jmontor66@iibiomedicas.unam.mx

* Correspondence: *Corresponding author: Jorge Morales Montor (jmontor66@iibiomedicas.unam.mx) email@e-mail.com;

\begin{abstract}
Public concern has emerged about the effects of endocrine disruptor compounds (EDCs) on neuropsychiatric disorders. Preclinical evidence suggests that exposure to EDCs is associated with the development of the major depressive disorder (MDD) and could result in neural degeneration. The interaction of EDCs with hormonal receptors is the best-described mechanism of their biological activity. However, the dysregulation of the hypothalamic-pituitary-gonadal adrenal axis has been reported and linked to neurological disorders. On the other hand, at a worldwide level and in Mexico, the incidence of MDD has recently been increasing. Of note, in Mexico, there are no clinical associations on blood levels of EDCs and the incidence of the MDD. Methodology: Thus, we quantified for the first time the serum levels of parent compounds of two bisphenols and four phthalates in patients with MDD. Results: The levels of di-ethyl-hexyl-phthalate (DEHP), butylbenzyl-phthalate (BBP), di-n-butyl phthalate (DBP), and di-ethyl-phthalate (DEP), bisphenol A (BPA), and bisphenol S (BPS) were determined with a gas chromatograph-mass spectrometer. Results/ conclusion: We found significant differences between concentrations of BBP between controls and patients with MDD.

Interestingly, the serum levels of this compound have a dysmorphic behavior, being much higher in women than in men. We did not observe significant changes in the serum concentrations of the other phthalates or bisphenols tested, neither when comparing healthy and sick subjects nor when they were compared by gender. The results point out that BBP has a critical impact on the etiology of MDD disorder in Mexican patients, specifically in women.
\end{abstract}

Keywords: depression, serum levels, phthalates, bisphenols.

\section{Introduction}

According to World Health Organization (WHO), MDD is a mood disorder with hormonal, neurochemical, and inflammatory alterations [1-6]. It has been reported that MDD is present twice in females than in males [7]. It is recognized that age, genetic elements, sociocultural factors, and hormonal status can contribute to the sex difference in MDD. Nevertheless, environmental pollutants (industrial compounds, plastics and plasticizers, fungicides, and pesticides) have recently emerged as a crucial factor that must be considered in this disorder [8]. 
Currently, exposure to different environmental pollutants known as EDCs has been associated with different neurological alterations including attention deficit/hyperactivity disorder and autism spectrum disorder [9,10]. Certain EDCs such as DEHP can dysregulate the hypothalamic-pituitary-gonadal adrenal axis, which is crucial for reproductive and neuronal processes [11]. In particular, phthalates and bisphenols are ubiquitous environmental pollutants that have been related to the homeostatic imbalance of different systems [12-15]. Both types of compounds are found in daily-use products [16,17]. Worldwide, their presence has expanded to different sources, including food, air, and water, representing a significant health issue [15]. These compounds are lipophilic, which allows them to be easily absorbed by the skin. In addition, changes in $\mathrm{pH}$ or temperature favor their release from the plastic matrix to which they are attached, causing their ingestion through the oral cavity. Once inside the body, they can bind to steroid receptors, which, in turn, allows them to differentially modulate the signaling pathways generally activated by endogenous ligands [18,19]. Of note, exposure to both classes of plasticizers, bisphenols, and phthalates, during critical periods can predispose to disturbing human health effects [15]. This could suggest that their mother-infant contact route, intake at the perinatal stage, and adulthood could be associated with the predisposition to develop MDD.

MDD involved alterations in neurotransmitter systems, including noradrenergic, cholinergic, serotonergic, and dopaminergic pathways. In this sense, estrogens such estradiol (E2) increases the effectiveness of the serotoninergic system through the transcriptional modulation of 5-HT transporter (SERT or 5-HTT), tryptophan hydroxylase-2 (TPH2), and monoamine oxidase A and B (MAO), whereby, important antidepressant functions have been attributed to E2 [20-25]. In fact, the combination serotonin reuptake inhibitors (SSRIs), such as fluoxetine (FLX) and sertraline with E2 as an adjuvant fashion, have demonstrated promising results for elderly depressed women [26,27].

Of note, the aberrant function of MAOs has a fundamental role in the promotion and maintenance of MDD [28]. Supporting the above, it has been documented that MDD in females generally occurs during periods of hormonal (E2) perturbation [29-31]. Until now, there is no existing literature about the modulation of different components of the serotonergic system by the EDCs. However, EDCs interrupt the regular action of hormones, thus, they may affect the function of hormone-sensitive organs, including the brain. For instance, the exposure to EDCs in young mice rats can promote incomplete methylation of specific gene regions in the brain, impairing the neural growth and brain functions even across generations [32,33]; which might have a potential impact on the development of depression.

On the other hand, estrogen receptors (ERs) are expressed in different subsets of immune cells. Thus, estrogens can exert both, anti- and pro-inflammatory effects, depending on the cell context [34]. In addition the effects of E2 have also been related to the control of Th1 and Th2 responses [35]. Currently, the prevalence of the Th2 response has been clinically associated with the presence of MDD [36]. The effects of different EDCs on the shift of Th1 and Th2 responses have also been little studied. Postnatally female mice exposed to BPA have been associated with a polarization of the Th2 response [37]. In addition, phthalates can also promote a Th2 differentiation, the above has been reported in vivo, in vitro, and epidemiological studies in asthma [38,39].

Some research groups have examined the serum levels of E2 in patients with MDD, which are around 85-127 pg/ml and $55 \mathrm{pg} / \mathrm{ml}$ in the female and male population, respectively [40,41]. To date there are many studies about the quantification of phthalates and bisphenols in different biological fluids [42-45]. Nevertheless, there are no reports on their serum levels in patients with MDD around the world. Considering that these substances are found in many sources, and humans are constantly exposed to them, we decided to evaluate the serum concentrations of specific phthalates and bisphenols in patients with MDD in Mexico City. In the case of phthalates, 2 of them correspond to compounds with high molecular weight, found mainly in plastic devices; and the other two compounds correspond to low molecular weight, which are primarily found in cosmetic and personal use products. Concerning bisphenols, we measured the BPA and one of its primary analogs, BPS.

It is also important to note that in most studies, serum, or urinary levels of different hydroxylated or glucuronide metabolites of phthalates and bisphenols have been evaluated $[42,43,46]$. In the case of BPA, it is often assumed that after its exposure, it is rapidly metabolized to an inactive metabolite (glucuronic form) and excreted from the body with a half-life around 5 hours $[47,48]$. Of note, the half-life of phthalates depends on their molecular weight. Low molecular weights (DEP and DBP) are hydrolyzed and quickly converted in monoesters and excreted, meanwhile phthalates with high molecular weight (DEHP and BBP) are also first hydrolyzed and then metabolized in a multistep oxidative pathway $[43,49]$. However, it has been reported that the enzyme $\beta$-glucuronidase is present in various tissues, this enzyme can give the unconjugated form of BPA (active metabolite) and release into the body [50]. Due to 
its lipophilic character, BPA can migrate and store in different tissues, bringing the concept of bioaccumulation into the body. Scientific evidence has questioned this notion with different arguments: Humans and animals are in constant exposure to BPA and other types of substances. In general, since it has been demonstrated that BPA can be reverted to its active form, then could the unconjugated form of the parental metabolites be measured?, Would it be necessary to quantify different pollutants at the blood level and in tissues where they bioaccumulate to have an idea of the possible global damage in the body? [47]. Considering this assumption, we decided to evaluate the serum concentrations of parent compounds of phthalates and bisphenols instead of their metabolites in patients with MDD.

\section{Materials and Methods}

\subsection{Patients / Study population}

The outpatient clinic of the Instituto Nacional de Psiquiatria Ramón de Fuente in Mexico City assessed 98 individuals and recruited 14 Mexican patients that met inclusion criteria from January 2015 to December 2018. Patient recruitment was conducted according to the Declaration of Helsinki, and the clinical experimental procedures set out in NC150048SECITI research protocol, approved by the ethics committee of Instituto Nacional de Psiquiatría, México.

The inclusion criteria for this study included participants without medical illnesses, without a history of allergies or allergic reactions. Criteria also included low coffee (2 cups/day), alcohol (3 measures/week), or tobacco (7 cigarettes/day) intake. Women who were pregnant were excluded from the study.

Psychiatrists diagnosed all subjects from Instituto Nacional de Psiquiatría, who applied the validated Spanish version of the Mini-International Neuropsychiatric Interview [51-53], a standardized diagnostic interview based on DSM-IV criteria. Clinical status was measured with the 21-items Hamilton Depression Scale (HDRS) and the 21items Beck Depression Inventory (BDI) [54-56]. Blood samples of different patients between 30-65 years with MDD were collected for respectively, analysis. Table 1 shows Demographic characteristics of the patients.

\subsection{Healthy volunteers}

53 healthy volunteers were matched by age with patients with MDD. Healthy volunteers were recruited from the general population from January 2015 to December 2018. Clinical and laboratory assessments of control subjects fell within typical reference values (data not shown). The MINI confirmed that they did not have any mental disorder and all of them were free of any medication at least three weeks before blood and urine sampling. The demographic characteristics of this group are shown in Table 1.

Table 1. Demographic characteristic of study sample

\begin{tabular}{|l|c|c|}
\hline & $\begin{array}{c}\text { Patients } \\
\mathrm{n}=14\end{array}$ & $\begin{array}{c}\text { Healthy volunteers } \\
\mathrm{n}=53\end{array}$ \\
\hline Age (years) & $34.1 \pm 9.1$ & \\
\hline Sex (male/female) & $4 / 10$ & \\
\hline BMI $\left(\mathrm{Kg} / \mathrm{m}^{2}\right)$ & $24.8 \pm 2.5$ & NA \\
\hline Education (years) & $10.6 \pm 4.93$ & NA \\
\hline Family history (yes/no) & $5 / 9$ & NA \\
\hline First episode & 6 & \\
\hline Recurrent episode & 8 & \\
\hline
\end{tabular}




\subsection{Collection of serum samples}

For this study, after a detailed explanation of the study aims, all participants signed a written informed consent for experimentation with human samples. This work was conducted in accordance with the Declaration of Helsinki, and the Ethics Committee approved the protocol of Instituto Nacional de Psiquiatria Ramón de la Fuente Muñiz.

\subsection{Sample treatment}

Serum samples healthy individuals and patients with depression were centrifugated to obtain the serum. After that, an organic methanol-based extraction protocol was performed, getting a dry lyophilized extract [57]. The extracts were reconstituted and derivatized by adding $50 \mu \mathrm{l}$ of N-Methyl-N-trimethylsilyl-trifluoroacetamide (MSTFA) and heating at $80^{\circ} \mathrm{C}$ for 30 minutes in a dry block heater. After derivatization, $40 \mu \mathrm{l}$ were taken and transferred into a $200 \mu \mathrm{l}$ vial insert. $10 \mu \mathrm{l}$ of deuterated dicyclohexyl phthalate $(2.5 \mathrm{ng} / \mu \mathrm{l})$ were added as internal standards immediately prior the injection into a gas chromatograph coupled to a mass spectrometer (GC-MS).

\subsection{Data analysis}

Chromatographic analyses were carried out with Enhanced Data Analysis software (Agilent Technologies, USA). The peak identity was analyzed comparing the retention time and analyte standards, which was confirmed by mass spectrum. Internal standard calibration curves were also employed for quantitation.

\subsection{Reagents and chemicals}

Phthalate diester standards diethyl phthalate (DEP), di-n-butyl phthalate (DBP), butyl-benzyl phthalate (BBP), and bis-ethyl-hexyl phthalate (DEHP) were purchased from Chemservice Inc., Deuterated dicyclo-hexyl phthalate was from Accustandard. Bisphenol-A, Bisphenol-S, MSTFA were acquired from Sigma-Aldrich. Methanol and ether were purchase from Merk-Millipore.

\subsection{GC-MS conditions}

Gas chromatograph-mass spectrometer analyses were performed (7890-B/5977-B), Agilent Technologies, USA) with a quadrupole mass filter. Each sample was analyzed in duplicate. A 60 m DB-35ms capillary column (250 $\mu \mathrm{m} \times 0.25 \mu \mathrm{m}$ ) was used for chromatographic separation. High purity helium was used as the carrier gas at a flow rate of $1.2 \mathrm{~mL} / \mathrm{min}$. The initial oven temperature was set to $80{ }^{\circ} \mathrm{C}$ for $1 \mathrm{~min}$ and then increased at $20^{\circ} \mathrm{C} / \mathrm{min}$ to $320^{\circ} \mathrm{C}$, with a $7 \mathrm{~min}$ hold. The mass spectrometer was operated in electronic ionization mode $(70 \mathrm{eV})$ in scan mode (25-430 Da). The temperatures were $300{ }^{\circ} \mathrm{C}$ for the transfer line, $230{ }^{\circ} \mathrm{C}$ for the ion source, and $150{ }^{\circ} \mathrm{C}$ for the quadrupole.

\subsection{Statistical analysis}

The statistical differences about the concentration of different compounds among the groups were determined by a non-parametric analysis, using the Mann-Whitney U test for paired comparisons. For the analysis, the specialized software package GraphPad Prism 6 version (San Diego, California USA) was used. $p<0.05$ was considered statistically significant.

\section{Results}

\subsection{Serum levels of environmental pollutants in healthy individuals and in patients with MDD}

We analyzed the serum concentrations of different phthalates in the control group (C) and in patients with depression (P), (Figure 1). The results showed that both controls and patients have similar basal levels ( 200 $\mathrm{ng} / \mathrm{mL}$ ) of all phthalates tested. However, significant differences between the controls and patients were found in the levels of BBP. It should be noted that in patients with depression there were 10 times lower ranges $(<500$ $\mathrm{ng} / \mathrm{mL}$ ) of BBP compared to healthy individuals ( 5000 ng/mL) (Figure 1D). 
A)

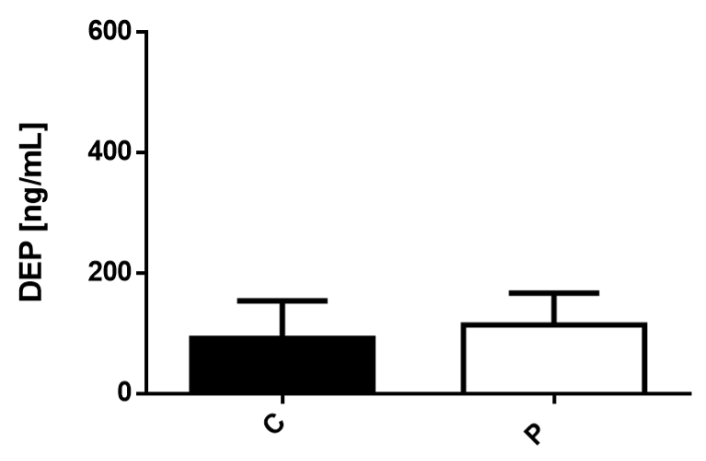

C)

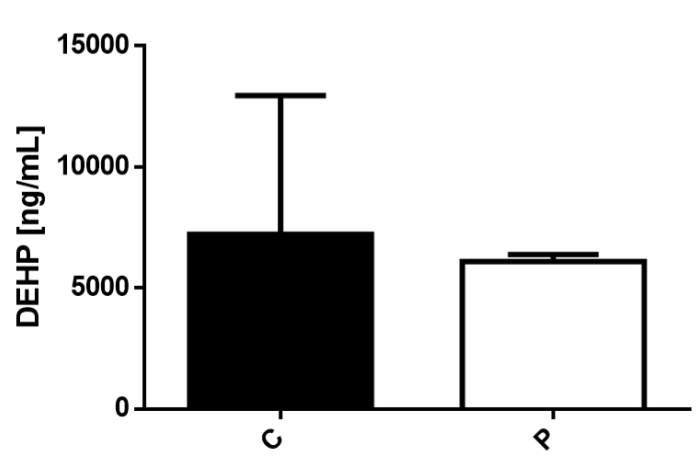

B)

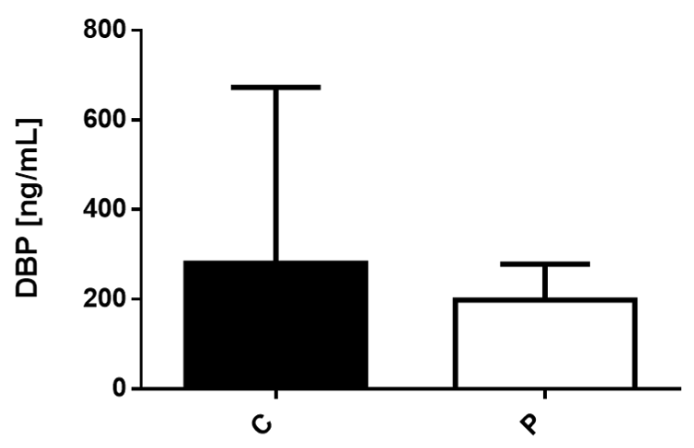

D)

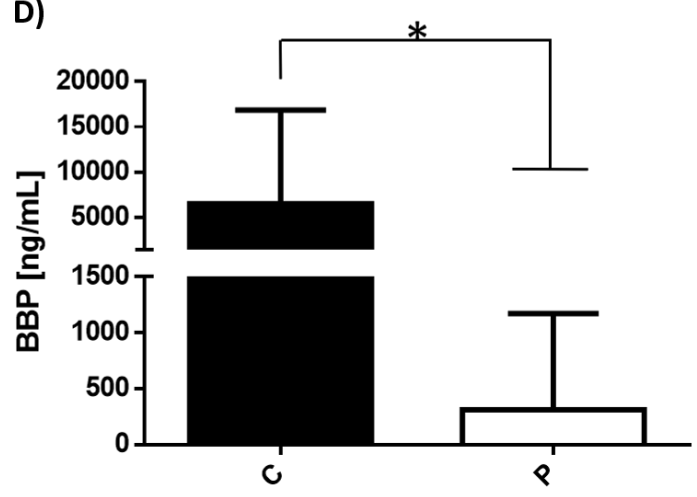

Figure 1. Levels of phthalates in controls and patients with depression. Serum concentration levels of phthalates (A) DEP, (B) DBP, (C) DEHP, and (D) BBP were measured in healthy individuals (C) (53 subjects / black bar) and sick individuals (14 subjects / white bar). Bars represent the mean \pm S.D. ${ }^{*} \mathrm{p}<0.05$ was considered statistically significant.

We also analyzed the serum levels of BPA and BPS in the two experimental groups. (Figure 2). BPS levels were low in both controls and sick individuals. However, there was a significant difference between them, showing higher levels in patients with depression than that in the healthy counterpart (Figure 2B). The levels of BPA were not significant differences between the two experimental conditions.

A)

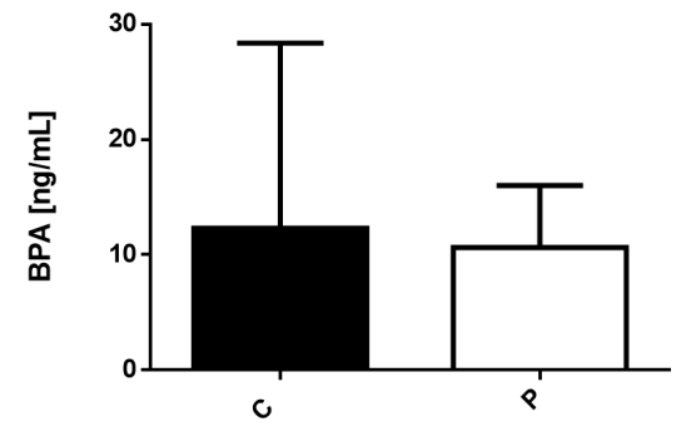

B)

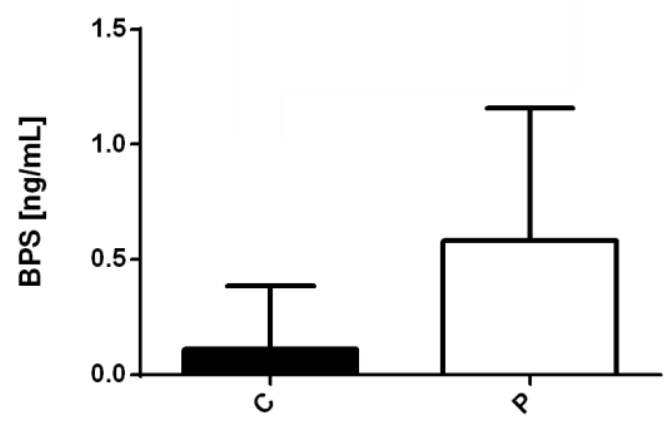

Figure 2. Levels of bisphenols in controls and patients with depression. Serum concentration levels of (A) BPA, (B) BPS were measured in healthy individuals (C) (53 subjects / black bar) and sick individuals (14 subjects / white bar). Bars represent the mean \pm S.D. ${ }^{*} \mathrm{p}<0.05$ was considered statistically significant. 


\subsection{Serum levels of environmental pollutants in patients with MDD separated by gender.}

Because the incidence of depression has a dimorphic tendency, we consider important to compare the levels of pollutants in men and women patients with depression. The results showed that DEP, DPB, and DEHP serum levels were similar in both genders. However, outstandingly, the levels of BBP were significantly different in women with depression, showing a greater increase ( $>50$-fold) as compared with men.

A)

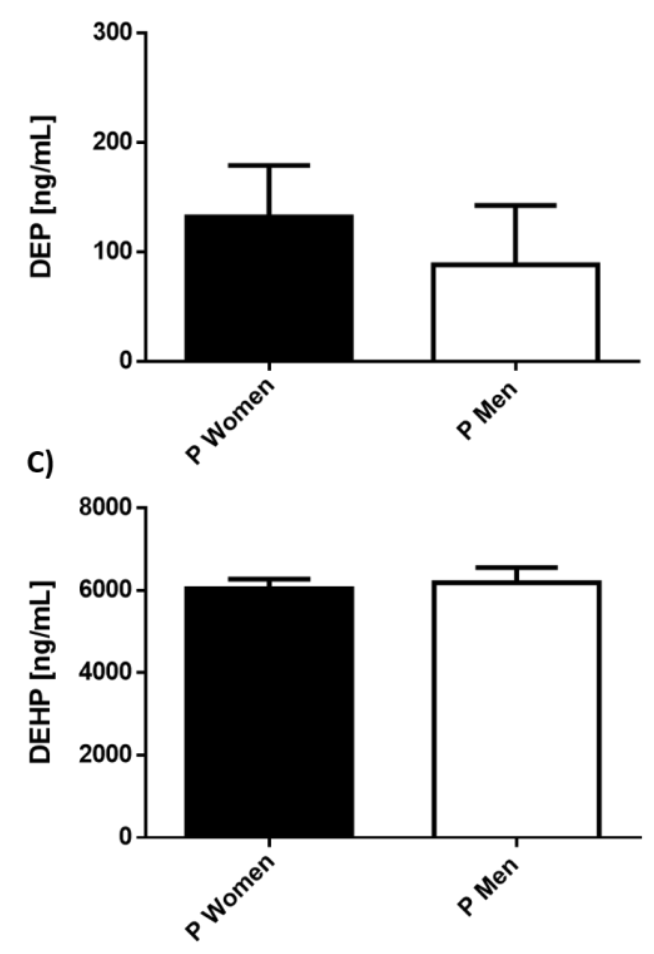

B)

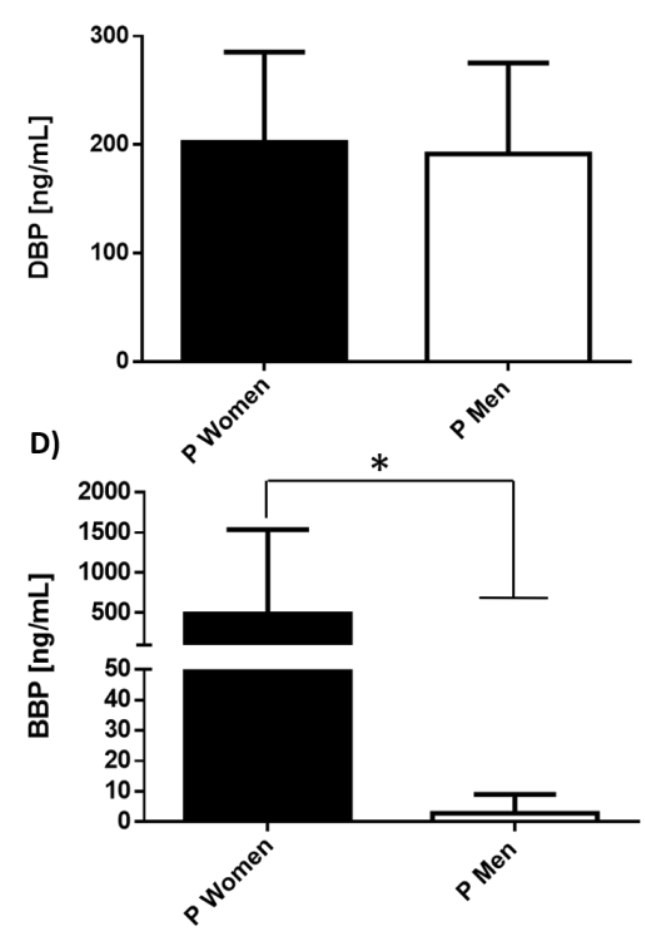

Figure 3. Levels of phthalates in male and female patients with depression. Serum concentration levels of phthalates (A) DEP, (B) DBP, (C) DEHP, (D) BBP were measured in women (9 subjects / black bar) and men (5 subjects / white bar). Bars represent the mean \pm S.D. ${ }^{*} p<0.05$ was considered statistically significant.

Concerning bisphenols, there were no dimorphic differences, and the serum values found were similar in men and women, Figure 4.

A)

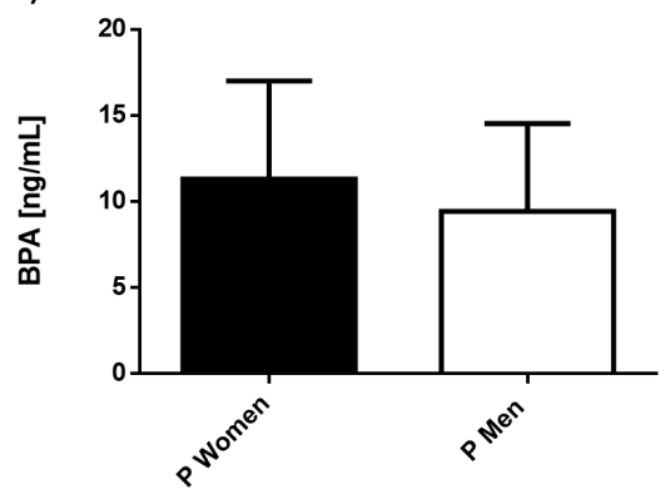

B)

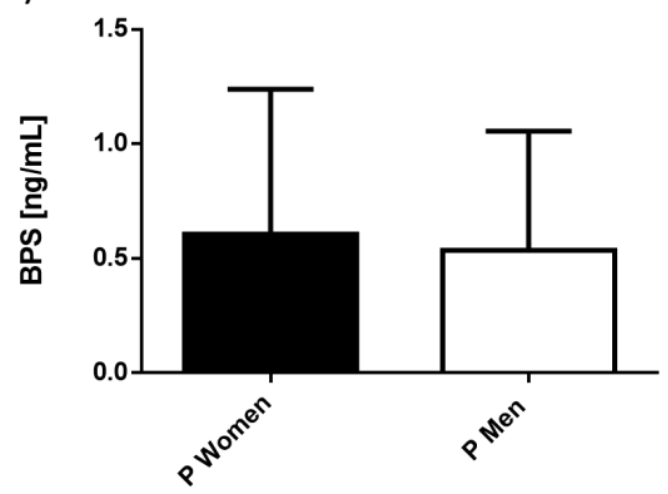

Figure 4. Levels of bisphenols in male and female patients with depression. Serum concentration levels of phthalates (A) BPA, (B) BPS were measured in women (9 subjects / black bar) and men (5 subjects / white bar). Bars represent the mean \pm S.D. ${ }^{*} \mathrm{p}<0.05$ was considered statistically significant. 


\section{Discussion}

This study determined the serum concentration of parent compounds of different phthalates and bisphenols in healthy individuals and patients with MDD.

MDD is a mood disorder of multifactorial origin, which is considered a global health emergency due to the number of patients worldwide and the costs they cause to public health in all countries. Research on this condition has focused on aspects of genetic susceptibility, hormonal, neurochemical, and inflammatory alterations [1,2]. MDD is characterized by the decrease in the production of biogenic amines and globally is accompanied by the dysfunction of the neuroimmuno-endocrine systems. In this regard, estradiol (E2) is widely known to play an important role in the regulation of critical components of the optimal function of the serotonergic system and enzymes that degrade monoamines [2]. Despite the enormous effort in pharmacological research for MDD developed since the last century, there are still no effective pharmacological treatments and therapeutic adherence is low, which increases therapeutic failure. All above contributes to having a high number of patients with this condition.

One point to consider is that, despite reports on the possible participation of environmental pollutants such as BPA, DBP, BBP, and DEHP in the establishment and aggravation of MDD, few studies evaluate their levels in properly diagnosed patients and that explore the mechanisms associated with the development of the symptoms of these conditions. Considering that various EDCs such as phthalates and bisphenols mimic hormone actions, we decided to evaluate the concentrations of various phthalates and 2 bisphenols in the serum of patients with depression and to compare their levels with healthy individuals, as well as between male and female individuals. It should be noted that the compounds we choose are widely used in commonly used products.

We mainly found significant differences between concentrations of BBP between controls and patients with MDD. Interestingly, the serum levels of this compound have a dimorphic behavior, being much higher in women than in men. BBP is a high-molecular-weight phthalate with an asymmetrical structure, used as a plasticizer in PVC products [58]. BBP has demonstrated an etiological association with endometriosis that directly correlates with high blood levels of this contaminant [59]. Supporting the above, BBP can modulate different hormone-dependent genes it has been demonstrated to be the most active estrogenic phthalate among others [60,61]. Of note, different phthalates have been shown to decrease serum levels of E2 with a concomitant prolonged estrous cycle, causing anovulation in rats. This effect was due to the suppression of aromatase gene expression, the responsible enzyme of E2 synthesis [62]. Considering that the optimal levels of E2 are implicated in the regulation of multiple systems and have an essential antidepressant function, it will be important to determine levels of contaminants (EDCs) and E2 in patients with MDD simultaneously; to be able to replace the basal levels of this hormone. In addition, exposure to different phthalates has harmful pleiotropic actions [63], which is still unknown at the brain level.

Serum levels of different metabolites of BBP have been determined, in women $(\sim 140 \mathrm{ng} / \mathrm{ml})$ and in men $(85-100 \mathrm{ng} / \mathrm{ml})$ $[64,65]$. In this regard, we observed a 35 times higher concentration of this compound at the serum level in the female population. However, it is important to remark that we measured the parent compound instead of some metabolites. Our results can be supported in previous reports where women have greater exposure to phthalates than males of the same age, possibly due to an increased use of cosmetics and medication, considering that phthalates are employed in the manufacture of capsules or in the drug packaging [66,67]. A recent study by Shao-hui Zhang 2018 et al., evaluated the distribution of different phthalates (parent compounds not their metabolites) in the serum of patients with high blood pressure in China [68]. Interestingly, they found deficient concentrations of BBP $(\sim 0.5 \mu \mathrm{g} / \mathrm{L})$ in the population included. However, it is important to highlight that of 454 participants, 336 were men and 138 were women [68], supporting our results.

On the other hand, an explanation why BBP can induce MDD is based on its lipophilic characteristics [69], which could favor its migration and storage at the central nervous system level. In addition, BBP exposure also causes a decrease in serotonin (5-HT) levels [70], which then, in turn, attends to the activation of adenylyl cyclase by G protein-coupled receptors (GPCRs). This enzyme catalyzes the formation of cAMP from ATP in an energy-dependent manner. Thus, the activating of protein kinase A can be impaired, which decreases the levels of CREB phosphorylation. Concomitantly, the decrease of PCREB attenuates the effects of CREB downstream. Thus, oxidative damage and pathological alterations in mice brains and the impaired behavioral performance were evidence [70].

Regarding the cellular effects of other phthalates, it is known that DBP increases the concentration of reactive oxygen intermediates [71], which might also cause significant damage in neurons. There are also reports about different 
phthalates highlighting the alterations that phthalates evoked in sex hormones and in different enzymes involved in their biosynthesis or catabolism in male and female animal models [72]. The disturbances in different hormone levels found on in vivo models might favor a physiological condition comparable with MDD disease in humans such as cognitive decline, impaired learning, and memory. Supporting these facts, perinatal phthalate exposure seems to induce hippocampal impairment involving downregulation of androgen and estrogen receptor expression in mice [73], effects caused by the crossing of phthalates through the placental barrier [74,75], which suggests that phthalates also cross the blood-brain barrier. Moreover, exposure to phthalates and other EDCs in early periods of life can affect the neural function due to impairment of methylation profile in the brain [76], conferring greater susceptibility to neuronal disorders such as MDD into adulthood.

On the other hand, not many studies have evaluated the dimorphic role of phthalates in the brain and its functions in rats or mice; however, there is evidence that the postanal exposure of DHEP in rats may harm the development of the hippocampus in males but not in females [77]. The explanatory mechanism by which DEHP caused these effects was that in the female rat hippocampus, DEHP alters the lipid profile, leading to elevated levels of phosphatidylcholine and sphingomyelin. In contrast, the effect of DEHP was absent in the hippocampus of male rats. Thus, the authors postulated that the upregulation of hippocampal lipids could have a neuroprotective role in DEHP-exposed female rats [78].

Regarding bisphenols, our results denoted that the levels of BPA and BPS in the individuals included were between 10 $\mathrm{ng} / \mathrm{ml}$ and $0.5 \mathrm{ng} / \mathrm{ml}$, respectively. They are close with the data reported by other authors in healthy individuals [7981]. However, we did not find significant differences between the levels of phthalates neither in healthy populations nor in patients with MDD. This may be due to the limited number of patients with this disease enrolled in this study. Recently, more biological evidence has linked the role of environmental exposure and the generation of disorders such as depression. Although there is still a lack of clinical data that strongly supports this relationship [82].

We consider that the present study offers clinical knowledge that strongly suggests that EDCs, particularly BBP, play an important role in the generation/promotion of psychiatric illnesses such as MDD. However, we are aware that this work has several limitations 1) we cannot compare the serum concentrations of EDCs with other works, as we measured the parent compounds and not the metabolites. However, the data obtained it is not very different from what was reported, 2) it will be essential to include more patients with MDD with making stronger assumptions. Finally, 3) the serum measure of E2, other hormones, neurotransmitters, lipid and methylation profile, or different cytokines will be important to give a global landscape about the effect of different EDCs and MDD.

\section{Conclusions}

Our results suggested that phthalate exposure, particularly BBP, might increase MDD in female adults. However, our findings warrant further studies in larger population

\section{Patents}

The outpatient clinic of the Instituto Nacional de Psiquiatria Ramón de Fuente in Mexico City assessed 98 individuals and recruited a total of 14 Mexican patients that met inclusion criteria from January 2015 to December 2018.

Author Contributions: Author Contributions: MSM: Conceptualization, methodology, project administration and writing; MIPA: Methodology and data analysis; LP: Methodology, supervision, data analysis and writing; EB: Resources; KENC: Methodology; OA: Experimentation, and data analysis, JMM: Conceptualization, methodology, project administration, writing, review and editing financial resources, supervision, funding acquisition. All authors have read and agreed to the published version of the manuscript

Funding: Funding: Grant IN-209719 from Programa de Apoyo a Proyectos de Innovación Tecnológica (PAPITT), Dirección General de Asuntos del Personal Académico (DGAPA), Universidad Nacional Autónoma de México (UNAM) and Grant FC2016-2125 from Fronteras en la Ciencia, Consejo Nacional de Ciencia y Tecnología (CONACYT), both to Jorge Morales-Montor.

Institutional Review Board Statement: Patient recruitment was conducted in accordance with the Declaration of Helsinki, and the clinical experimental procedures set out in NC150048SECITI research protocol, that was approved by the ethics committee of Instituto Nacional de Psiquiatría, México (protocol INP-19331, 01/01/2019).

Informed Consent Statement: Informed consent was obtained from all subjects involved in the study.

Conflicts of Interest: The authors declare that they have no competing financial or any interests. 


\section{References}

1. National Institutes of Health (US); Biological Sciences Curriculum Study. NIH Curriculum Supplement Series [Internet]. Bethesda (MD): National Institutes of Health (US); Information about Mental Illness and the Brain. Available from: https://www.ncbi.nlm.nih.gov/books/NBK20369/ 2007.

2. Vogelzangs, N.; Duivis, H.E.; Beekman, A.T.; Kluft, C.; Neuteboom, J.; Hoogendijk, W.; Smit, J.H.; de Jonge, P.; Penninx, B.W. Association of depressive disorders, depression characteristics and antidepressant medication with inflammation. Translational psychiatry 2012, 2, e79, doi:10.1038/tp.2012.8.

3. Pochigaeva, K.; Druzhkova, T.; Yakovlev, A.; Onufriev, M.; Grishkina, M.; Chepelev, A.; Guekht, A.; Gulyaeva, N. Hair cortisol as a marker of hypothalamic-pituitary-adrenal Axis activity in female patients with major depressive disorder. Metabolic brain disease 2017, 32, 577-583, doi:10.1007/s11011-017-9952-0.

4. Vreeburg, S.A.; Hoogendijk, W.J.; van Pelt, J.; Derijk, R.H.; Verhagen, J.C.; van Dyck, R.; Smit, J.H.; Zitman, F.G.; Penninx, B.W. Major depressive disorder and hypothalamic-pituitary-adrenal axis activity: results from a large cohort study. Archives of general psychiatry 2009, 66, 617-626, doi:10.1001/archgenpsychiatry.2009.50.

5. de Villiers, A.S.; Russell, V.A.; Carstens, M.E.; Searson, J.A.; van Zyl, A.M.; Lombard, C.J.; Taljaard, J.J. Noradrenergic function and hypothalamic-pituitary-adrenal axis activity in adolescents with major depressive disorder. Psychiatry research 1989, 27, 101-109, doi:10.1016/0165-1781(89)90125-x.

6. Okasha, T.A.; Sabry, W.M.; Hashim, M.A.; Abdeen, M.S.; Abdelhamid, A.M. Vitamin D serum level in major depressive disorder and schizophrenia. Middle East Current Psychiatry 2020, 27, 34, doi:10.1186/s43045-020-00043$\mathrm{y}$.

7. Global, regional, and national incidence, prevalence, and years lived with disability for 354 diseases and injuries for 195 countries and territories, 1990-2017: a systematic analysis for the Global Burden of Disease Study 2017. Lancet 2018, 392, 1789-1858, doi:10.1016/S0140-6736(18)32279-7.

8. In Depression in Parents, Parenting, and Children: Opportunities to Improve Identification, Treatment, and Prevention, England, M.J., Sim, L.J., Eds.; Washington (DC), 2009.

9. Shoaff, J.R.; Coull, B.; Weuve, J.; Bellinger, D.C.; Calafat, A.M.; Schantz, S.L.; Korrick, S.A. Association of Exposure to Endocrine-Disrupting Chemicals During Adolescence With Attention-Deficit/Hyperactivity Disorder-Related Behaviors. JAMA Network Open 2020, 3, e2015041-e2015041, doi:10.1001/jamanetworkopen.2020.15041.

10. de Cock, M.; Maas, Y.G.; van de Bor, M. Does perinatal exposure to endocrine disruptors induce autism spectrum and attention deficit hyperactivity disorders? Review. Acta Paediatr 2012, 101, 811-818, doi:10.1111/j.16512227.2012.02693.x.

11. Liu, T.; Jia, Y.; Zhou, L.; Wang, Q.; Sun, D.; Xu, J.; Wu, J.; Chen, H.; Xu, F.; Ye, L. Effects of Di-(2-ethylhexyl) Phthalate on the Hypothalamus-Uterus in Pubertal Female Rats. Int J Environ Res Public Health 2016, 13, 1130, doi:10.3390/ijerph13111130.

12. Konieczna, A.; Rutkowska, A.; Rachon, D. Health risk of exposure to Bisphenol A (BPA). Roczniki Panstwowego Zakladu Higieny 2015, 66, 5-11.

13. Thoene, M.; Dzika, E.; Gonkowski, S.; Wojtkiewicz, J. Bisphenol S in Food Causes Hormonal and Obesogenic Effects Comparable to or Worse than Bisphenol A: A Literature Review. Nutrients 2020, 12, 532, doi:10.3390/nu12020532.

14. Dutta, S.; Haggerty, D.K.; Rappolee, D.A.; Ruden, D.M. Phthalate Exposure and Long-Term Epigenomic Consequences: A Review. Front Genet 2020, 11, 405-405, doi:10.3389/fgene.2020.00405. 
15. Segovia-Mendoza, M.; Nava-Castro, K.E.; Palacios-Arreola, M.I.; Garay-Canales, C.; Morales-Montor, J. How microplastic components influence the immune system and impact on children health: Focus on cancer. Birth defects research 2020, 112, 1341-1361, doi:10.1002/bdr2.1779.

16. Geens, T.; Goeyens, L.; Covaci, A. Are potential sources for human exposure to bisphenol-A overlooked? International journal of hygiene and environmental health 2011, 214, 339-347, doi:10.1016/j.ijheh.2011.04.005.

17. Koniecki, D.; Wang, R.; Moody, R.P.; Zhu, J. Phthalates in cosmetic and personal care products: concentrations and possible dermal exposure. Environmental research 2011, 111, 329-336, doi:10.1016/j.envres.2011.01.013.

18. Acconcia, F.; Pallottini, V.; Marino, M. Molecular Mechanisms of Action of BPA. Dose-response : a publication of International Hormesis Society 2015, 13, 1559325815610582, doi:10.1177/1559325815610582.

19. Balaguer, P.; Delfosse, V.; Grimaldi, M.; Bourguet, W. Structural and functional evidences for the interactions between nuclear hormone receptors and endocrine disruptors at low doses. Comptes rendus biologies 2017, 340, 414-420, doi:10.1016/j.crvi.2017.08.002.

20. M. Archer, J.S. Relationship Between Estrogen, Serotonin and Depression. Menopause 1997, 4.

21. Ma, Z.-Q.; Violani, E.; Villa, F.; Picotti, G.B.; Maggi, A. Estrogenic control of monoamine oxidase A activity in human neuroblastoma cells expressing physiological concentrations of estrogen receptor. European Journal of Pharmacology 1995, 284, 171-176, doi:https://doi.org/10.1016/0014-2999(95)00387-Z.

22. Hernandez-Hernandez, O.T.; Martinez-Mota, L.; Herrera-Perez, J.J.; Jimenez-Rubio, G. Role of Estradiol in the Expression of Genes Involved in Serotonin Neurotransmission: Implications for Female Depression. Current neuropharmacology 2019, 17, 459-471, doi:10.2174/1570159X16666180628165107.

23. Bethea, C.L.; Smith, A.W.; Centeno, M.L.; Reddy, A.P. Long-term ovariectomy decreases serotonin neuron number and gene expression in free ranging macaques. Neuroscience 2011, 192, 675-688, doi:10.1016/j.neuroscience.2011.06.003.

24. Hiroi, R.; Handa, R.J. Estrogen receptor-beta regulates human tryptophan hydroxylase-2 through an estrogen response element in the 5' untranslated region. Journal of neurochemistry 2013, 127, 487-495, doi:10.1111/jnc.12401.

25. Zhang, Z.; Chen, K.; Shih, J.C.; Teng, C.T. Estrogen-related receptors-stimulated monoamine oxidase B promoter activity is down-regulated by estrogen receptors. Mol Endocrinol 2006, 20, 1547-1561, doi:10.1210/me.2005-0252.

26. Schneider, L.S.; Small, G.W.; Clary, C.M. Estrogen replacement therapy and antidepressant response to sertraline in older depressed women. The American journal of geriatric psychiatry : official journal of the American Association for Geriatric Psychiatry 2001, 9, 393-399.

27. Schneider, L.S.; Small, G.W.; Hamilton, S.H.; Bystritsky, A.; Nemeroff, C.B.; Meyers, B.S. Estrogen replacement and response to fluoxetine in a multicenter geriatric depression trial. Fluoxetine Collaborative Study Group. The American journal of geriatric psychiatry : official journal of the American Association for Geriatric Psychiatry 1997, 5, 97-106.

28. Yeung, A.W.K.; Georgieva, M.G.; Atanasov, A.G.; Tzvetkov, N.T. Monoamine Oxidases (MAOs) as Privileged Molecular Targets in Neuroscience: Research Literature Analysis. Frontiers in Molecular Neuroscience 2019, 12, doi:10.3389/fnmol.2019.00143.

29. Schmidt, P.J.; Rubinow, D.R. Sex hormones and mood in the perimenopause. Annals of the New York Academy of Sciences 2009, 1179, 70-85, doi:10.1111/j.1749-6632.2009.04982.x.

30. Maki, P.M.; Kornstein, S.G.; Joffe, H.; Bromberger, J.T.; Freeman, E.W.; Athappilly, G.; Bobo, W.V.; Rubin, L.H.; Koleva, H.K.; Cohen, L.S.; et al. Guidelines for the Evaluation and Treatment of Perimenopausal Depression: 
Summary and Recommendations. J Womens Health (Larchmt) 2019, 28, 117-134, doi:10.1089/jwh.2018.27099.mensocrec.

31. Gordon, J.L.; Girdler, S.S.; Meltzer-Brody, S.E.; Stika, C.S.; Thurston, R.C.; Clark, C.T.; Prairie, B.A.; Moses-Kolko, E.; Joffe, H.; Wisner, K.L. Ovarian hormone fluctuation, neurosteroids, and HPA axis dysregulation in perimenopausal depression: a novel heuristic model. The American journal of psychiatry 2015, 172, 227-236, doi:10.1176/appi.ajp.2014.14070918.

32. Shutoh, Y.; Takeda, M.; Ohtsuka, R.; Haishima, A.; Yamaguchi, S.; Fujie, H.; Komatsu, Y.; Maita, K.; Harada, T. Low dose effects of dichlorodiphenyltrichloroethane (DDT) on gene transcription and DNA methylation in the hypothalamus of young male rats: implication of hormesis-like effects. The Journal of toxicological sciences 2009, 34, 469-482, doi:10.2131/jts.34.469.

33. Yaoi, T.; Itoh, K.; Nakamura, K.; Ogi, H.; Fujiwara, Y.; Fushiki, S. Genome-wide analysis of epigenomic alterations in fetal mouse forebrain after exposure to low doses of bisphenol A. Biochemical and biophysical research communications 2008, 376, 563-567, doi:10.1016/j.bbrc.2008.09.028.

34. Segovia-Mendoza, M.; Morales-Montor, J. Immune Tumor Microenvironment in Breast Cancer and the Participation of Estrogen and Its Receptors in Cancer Physiopathology. Frontiers in immunology 2019, 10, 348, doi:10.3389/fimmu.2019.00348.

35. Bereshchenko, O.; Bruscoli, S.; Riccardi, C. Glucocorticoids, Sex Hormones, and Immunity. Frontiers in immunology 2018, 9, doi:10.3389/fimmu.2018.01332.

36. Pavon, L.; Sandoval-Lopez, G.; Eugenia Hernandez, M.; Loria, F.; Estrada, I.; Perez, M.; Moreno, J.; Avila, U.; Leff, P.; Anton, B.; et al. Th2 cytokine response in Major Depressive Disorder patients before treatment. Journal of neuroimmunology 2006, 172, 156-165, doi:10.1016/j.jneuroim.2005.08.014.

37. Nava-Castro, K.E.; Togno-Peirce, C.; Palacios-Arreola, M.I.; Del Rio-Araiza, V.H.; Hernandez-Bello, R.; Morales Montor, J. Bisphenol A induces protection through modulation of the immune response against the helminth parasite Taenia crassiceps. Parasite immunology 2020, 42, e12733, doi:10.1111/pim.12733.

38. Bornehag, C.G.; Nanberg, E. Phthalate exposure and asthma in children. International journal of andrology 2010, 33, 333-345, doi:10.1111/j.1365-2605.2009.01023.x.

39. Hansen, J.F.; Nielsen, C.H.; Brorson, M.M.; Frederiksen, H.; Hartoft-Nielsen, M.-L.; Rasmussen, Å.K.; Bendtzen, K.; Feldt-Rasmussen, U. Influence of phthalates on in vitro innate and adaptive immune responses. PloS one 2015, 10, e0131168-e0131168, doi:10.1371/journal.pone.0131168.

40. Flores-Ramos, M.; Burrola-Suárez, M.A.; Guiza-Zayas, R.; Enciso-Araujo, J.M.; Islas-Preciado, D.; Estrada, C.E. Evaluation of hormonal and metabolic factors related to depression in reproductive age women. Salud Mental 2020, $43,35-41$.

41. Findikli, E.; Kurutas, E.B.; Camkurt, M.A.; Karaaslan, M.F.; Izci, F.; Fındıklı, H.A.; Kardaş, S.; Dag, B.; Altun, H. Increased Serum G Protein-coupled Estrogen Receptor 1 Levels and Its Diagnostic Value in Drug Naïve Patients with Major Depressive Disorder. Clin Psychopharmacol Neurosci 2017, 15, 337-342, doi:10.9758/cpn.2017.15.4.337.

42. Silva, M.J.; Reidy, J.A.; Herbert, A.R.; Preau, J.L.; Needham, L.L.; Calafat, A.M. Detection of Phthalate Metabolites in Human Amniotic Fluid. Bulletin of Environmental Contamination and Toxicology 2004, 72, 1226-1231, doi:10.1007/s00128-004-0374-4.

43. Wang, Y.; Zhu, H.; Kannan, K. A Review of Biomonitoring of Phthalate Exposures. Toxics 2019, 7, doi:10.3390/toxics7020021. 
44. Corrales, J.; Kristofco, L.A.; Steele, W.B.; Yates, B.S.; Breed, C.S.; Williams, E.S.; Brooks, B.W. Global Assessment of Bisphenol A in the Environment: Review and Analysis of Its Occurrence and Bioaccumulation. Dose Response 2015, 13, 1559325815598308-1559325815598308, doi:10.1177/1559325815598308.

45. Main, K.M.; Mortensen, G.K.; Kaleva, M.M.; Boisen, K.A.; Damgaard, I.N.; Chellakooty, M.; Schmidt, I.M.; Suomi, A.M.; Virtanen, H.E.; Petersen, D.V.; et al. Human breast milk contamination with phthalates and alterations of endogenous reproductive hormones in infants three months of age. Environ Health Perspect 2006, 114, 270-276, doi:10.1289/ehp.8075.

46. Inoue, H.; Yuki, G.; Yokota, H.; Kato, S. Bisphenol A glucuronidation and absorption in rat intestine. Drug metabolism and disposition: the biological fate of chemicals 2003, 31, 140-144, doi:10.1124/dmd.31.1.140.

47. Genuis, S.J.; Beesoon, S.; Birkholz, D.; Lobo, R.A. Human Excretion of Bisphenol A: Blood, Urine, and Sweat (BUS) Study. Journal of Environmental and Public Health 2012, 2012, 185731, doi:10.1155/2012/185731.

48. Volkel, W.; Colnot, T.; Csanady, G.A.; Filser, J.G.; Dekant, W. Metabolism and kinetics of bisphenol a in humans at low doses following oral administration. Chemical research in toxicology 2002, 15, 1281-1287, doi:10.1021/tx025548t.

49. Dutta, S.; Haggerty, D.K.; Rappolee, D.A.; Ruden, D.M. Phthalate Exposure and Long-Term Epigenomic Consequences: A Review. Frontiers in genetics 2020, 11, 405, doi:10.3389/fgene.2020.00405.

50. Ginsberg, G.; Rice, D.C. Does rapid metabolism ensure negligible risk from bisphenol A? Environ Health Perspect 2009, 117, 1639-1643, doi:10.1289/ehp.0901010.

51. Sheehan, D.V.; Lecrubier, Y.; Sheehan, K.H.; Amorim, P.; Janavs, J.; Weiller, E.; Hergueta, T.; Baker, R.; Dunbar, G.C. The Mini-International Neuropsychiatric Interview (M.I.N.I.): the development and validation of a structured diagnostic psychiatric interview for DSM-IV and ICD-10. The Journal of clinical psychiatry 1998, 59 Suppl 20, 2233; quiz 34-57.

52. Sheehan, D.V.; Sheehan, K.H.; Shytle, R.D.; Janavs, J.; Bannon, Y.; Rogers, J.E.; Milo, K.M.; Stock, S.L.; Wilkinson, B. Reliability and validity of the Mini International Neuropsychiatric Interview for Children and Adolescents (MINIKID). The Journal of clinical psychiatry 2010, 71, 313-326, doi:10.4088/JCP.09m05305whi.

53. Lecrubier, Y.; Sheehan, D.V.; Weiller, E.; Amorim, P.; Bonora, L.I.; Sheehan, K.; Janavs, J.; Dunbar, G.C. The MINI International Neuropsychiatric Interview (MINI). A Short Diagnostic Structured Interview: Reliability and Validity According to the CIDI. European Psychiatry 1997, 12, 224-231.

54. Carrozzino, D.; Patierno, C.; Fava, G.A.; Guidi, J. The Hamilton Rating Scales for Depression: A Critical Review of Clinimetric Properties of Different Versions. Psychotherapy and Psychosomatics 2020, 89, 133-150, doi:10.1159/000506879.

55. Beck, A.T.; Steer, R.A.; Ball, R.; Ranieri, W. Comparison of Beck Depression Inventories -IA and -II in psychiatric outpatients. Journal of personality assessment 1996, 67, 588-597, doi:10.1207/s15327752jpa6703_13.

56. Hamilton, M. A rating scale for depression. Journal of neurology, neurosurgery, and psychiatry 1960, 23, 56-62, doi:10.1136/jnnp.23.1.56.

57. Reis, A.; Rudnitskaya, A.; Blackburn, G.J.; Mohd Fauzi, N.; Pitt, A.R.; Spickett, C.M. A comparison of five lipid extraction solvent systems for lipidomic studies of human LDL. Journal of lipid research 2013, 54, 1812-1824, doi:10.1194/jlr.M034330.

58. Lyche, J.L.; Gutleb, A.C.; Bergman, A.; Eriksen, G.S.; Murk, A.J.; Ropstad, E.; Saunders, M.; Skaare, J.U. Reproductive and developmental toxicity of phthalates. Journal of toxicology and environmental health. Part B, Critical reviews 2009, 12, 225-249, doi:10.1080/10937400903094091. 
59. Reddy, B.S.; Rozati, R.; Reddy, B.V.; Raman, N.V. Association of phthalate esters with endometriosis in Indian women. BJOG : an international journal of obstetrics and gynaecology 2006, 113, 515-520, doi:10.1111/j.14710528.2006.00925.x.

60. Tyl, R.W.; Myers, C.B.; Marr, M.C.; Fail, P.A.; Seely, J.C.; Brine, D.R.; Barter, R.A.; Butala, J.H. Reproductive toxicity evaluation of dietary butyl benzyl phthalate (BBP) in rats. Reprod Toxicol 2004, 18, 241-264, doi:10.1016/j.reprotox.2003.10.006.

61. Harris, C.A.; Henttu, P.; Parker, M.G.; Sumpter, J.P. The estrogenic activity of phthalate esters in vitro. Environ Health Perspect 1997, 105, 802-811, doi:10.1289/ehp.97105802.

62. Lovekamp-Swan, T.; Davis, B.J. Mechanisms of phthalate ester toxicity in the female reproductive system. Environ Health Perspect 2003, 111, 139-145, doi:10.1289/ehp.5658.

63. Dutta, S.; Haggerty, D.K.; Rappolee, D.A.; Ruden, D.M. Phthalate Exposure and Long-Term Epigenomic Consequences: A Review. Front Genet 2020, 11, doi:10.3389/fgene.2020.00405.

64. Frederiksen, H.; Jorgensen, N.; Andersson, A.M. Correlations between phthalate metabolites in urine, serum, and seminal plasma from young Danish men determined by isotope dilution liquid chromatography tandem mass spectrometry. Journal of analytical toxicology 2010, 34, 400-410, doi:10.1093/jat/34.7.400.

65. Reddy, B.S.; Rozati, R.; Reddy, S.; Kodampur, S.; Reddy, P.; Reddy, R. High plasma concentrations of polychlorinated biphenyls and phthalate esters in women with endometriosis: a prospective case control study. Fertility and sterility 2006, 85, 775-779, doi:10.1016/j.fertnstert.2005.08.037.

66. Wittassek, M.; Koch, H.M.; Angerer, J.; Bruning, T. Assessing exposure to phthalates - the human biomonitoring approach. Molecular nutrition \& food research 2011, 55, 7-31, doi:10.1002/mnfr.201000121.

67. Hernandez-Diaz, S.; Mitchell, A.A.; Kelley, K.E.; Calafat, A.M.; Hauser, R. Medications as a potential source of exposure to phthalates in the U.S. population. Environ Health Perspect 2009, 117, 185-189, doi:10.1289/ehp.11766.

68. Zhang, S.H.; Shen, Y.X.; Li, L.; Fan, T.T.; Wang, Y.; Wei, N. Phthalate exposure and high blood pressure in adults: a cross-sectional study in China. Environmental science and pollution research international 2018, 25, 15934-15942, doi:10.1007/s11356-018-1845-1.

69. Dominguez-Romero, E.; Scheringer, M. A review of phthalate pharmacokinetics in human and rat: what factors drive phthalate distribution and partitioning? Drug metabolism reviews 2019, 51, 314-329, doi:10.1080/03602532.2019.1620762.

70. Min, A.; Liu, F.; Yang, X.; Chen, M. Benzyl butyl phthalate exposure impairs learning and memory and attenuates neurotransmission and CREB phosphorylation in mice. Food and chemical toxicology : an international journal published for the British Industrial Biological Research Association 2014, 71, 81-89, doi:10.1016/j.fct.2014.05.021.

71. Sicińska, P.; Kik, K.; Bukowska, B. Human Erythrocytes Exposed to Phthalates and Their Metabolites Alter Antioxidant Enzyme Activity and Hemoglobin Oxidation. Int J Mol Sci 2020, 21, 4480, doi:10.3390/ijms21124480.

72. Hlisníková, H.; Petrovičová, I.; Kolena, B.; Šidlovská, M.; Sirotkin, A. Effects and Mechanisms of Phthalates' Action on Reproductive Processes and Reproductive Health: A Literature Review. Int J Environ Res Public Health 2020, 17, 6811, doi:10.3390/ijerph17186811.

73. Xu, X.; Yang, Y.; Wang, R.; Wang, Y.; Ruan, Q.; Lu, Y. Perinatal exposure to di-(2-ethylhexyl) phthalate affects anxiety- and depression-like behaviors in mice. Chemosphere 2015, 124, 22-31, doi:10.1016/j.chemosphere.2014.10.056. 
74. Lin, H.; Yuan, K.; Li, L.; Liu, S.; Li, S.; Hu, G.; Lian, Q.Q.; Ge, R.S. In Utero Exposure to Diethylhexyl Phthalate Affects Rat Brain Development: A Behavioral and Genomic Approach. Int J Environ Res Public Health 2015, 12, 13696-13710, doi:10.3390/ijerph121113696.

75. Xu, Y.; Agrawal, S.; Cook, T.J.; Knipp, G.T. Di-(2-ethylhexyl)-phthalate affects lipid profiling in fetal rat brain upon maternal exposure. Archives of Toxicology 2007, 81, 57-62, doi:10.1007/s00204-006-0143-8.

76. Kajta, M.; Wojtowicz, A.K. Impact of endocrine-disrupting chemicals on neural development and the onset of neurological disorders. Pharmacological reports : PR 2013, 65, 1632-1639, doi:10.1016/s1734-1140(13)71524-x.

77. Smith, C.A.; Holahan, M.R. Reduced hippocampal dendritic spine density and BDNF expression following acute postnatal exposure to di(2-ethylhexyl) phthalate in male Long Evans rats. PloS one 2014, 9, e109522, doi:10.1371/journal.pone.0109522.

78. Smith, C.A.; Farmer, K.; Lee, H.; Holahan, M.R.; Smith, J.C. Altered Hippocampal Lipid Profile Following Acute Postnatal Exposure to Di(2-Ethylhexyl) Phthalate in Rats. Int J Environ Res Public Health 2015, 12, 13542-13559, doi:10.3390/ijerph121013542.

79. Yang, M.; Ryu, J.H.; Jeon, R.; Kang, D.; Yoo, K.Y. Effects of bisphenol A on breast cancer and its risk factors. Archives of toxicology 2009, 83, 281-285, doi:10.1007/s00204-008-0364-0.

80. Parada, H., Jr.; Gammon, M.D.; Ettore, H.L.; Chen, J.; Calafat, A.M.; Neugut, A.I.; Santella, R.M.; Wolff, M.S.; Teitelbaum, S.L. Urinary concentrations of environmental phenols and their associations with breast cancer incidence and mortality following breast cancer. Environment international 2019, 130, 104890, doi:10.1016/j.envint.2019.05.084.

81. Cobellis, L.; Colacurci, N.; Trabucco, E.; Carpentiero, C.; Grumetto, L. Measurement of bisphenol A and bisphenol B levels in human blood sera from healthy and endometriotic women. Biomedical chromatography : BMC 2009, 23, 1186-1190, doi:10.1002/bmc.1241.

82. Bosch, M.v.d.; Meyer-Lindenberg, A. Environmental Exposures and Depression: Biological Mechanisms and Epidemiological Evidence. Annual Review of Public Health 2019, 40, 239-259, doi:10.1146/annurev-publhealth040218-044106. 